\title{
Effect of Land-use Change Scenarios on Nutrients and TSS Loads
}

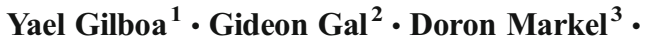 \\ Alon Rimmer ${ }^{2} \cdot$ Barry M. Evans $^{4} \cdot$ Eran Friedler $^{1}$
}

Received: 26 April 2015 / Accepted: 18 August 2015 / Published online: 28 August 2015

(C) Springer International Publishing Switzerland 2015

\begin{abstract}
The projected growth in population in Israel by $50 \%$ by 2030 will greatly enhance urban density and motivate increased urbanization of rural regions in the country. The Lake Kinneret watershed is a rural region of which only about $3 \%$ of the total area is used for residence, and currently, it is the least populated region in Israel. A significant land-use change and growth of urbanized regions is therefore expected in the near future, leading to changes in water quality management in the watershed. In this study, we attempted to quantify the effects of these possible changes in land-use on the flow and pollutant loads discharged from the watershed into Lake Kinneret. To that end, we calibrated and verified the AVGWLF (ArcView (GIS) Generalized Watershed Loading Function) model to simulate stream flows, sediment and nutrient loads under the conditions of a Mediterranean climate watershed. In addition to AVGWLF model, we used two external tools, namely: the HYdrological Model for Karst Environment (HYMKE) to predict daily flows of streams which were not simulated by the AVGWLF model, and a Mediterranean Multiplication Factor (MMF) which was used to improve sediment transport and nutrient load simulations. The combined suite of tools successfully simulated the observed data $\left(r^{2}>0.70\right.$ and Nash-Sutcliffe efficiency $>0.69$ for flowrate, sediment and nutrient), including extreme values. The successful combination of the models provides watershed and lake managers the ability to examine the potential land-use changes and their impact on the watershed and the lake downstream.
\end{abstract}

Yael Gilboa

ygilboa@tx.technion.ac.il

1 Faculty of Civil and Environmental Engineering, Technion - Israel Institute of Technology, Haifa 32000, Israel

2 Y. Allon Kinneret Limnological Laboratory, Israel Oceanographic \& Limnological Research, P.O. Box 447, Migdal 14950, Israel

3 Water Commission, Zahar Industrial Area, POB 623, Rosh Pina 12000, Israel

4 Penn State Institutes of the Environment, Land and Water Research Building, Pennsylvania State University, University Park, PA 16802, USA 
Keywords Watershed model $\cdot$ AVGWLF. HYMKE $\cdot$ Lake Kinneret watershed $\cdot$ Sediment and nutrient loads

\section{Introduction}

\subsection{Rationale}

Israel's population growth rate is one of the highest in the industrialized countries $(\sim 1.8 \% \mathrm{per}$ year). It also has one of the highest population densities in the world, with a country-wide average of 347 people $\mathrm{km}^{-2}$, but with a density of over 7,500 people $\mathrm{km}^{-2}$ in the Tel-Aviv region (Israel Central Bureau of Statistics, ICBS: http://www.cbs.gov.il/shnaton63/st0214.pdf). The ICBS projects that by the year 2030 Israel population will increase by approximately $50 \%$ compared with the current population (8.4 million people, 2015). While over $40 \%$ of the land in the greater Tel Aviv area is utilized for residential purposes, only $3 \%$ is utilized for this purpose in the Lake Kinneret (Lake Tiberias or the Sea of Galilee) watershed region (ICBS; Fig. 1). The high density in the central part of the country and the associated extremely high cost of housing is creating a need for new affordable housing around the country. A possible answer to this pressing need is building new affordable housing in rural areas of the country in and around small towns and villages. And indeed, the government is investing massively in upgrading transportation infrastructure to rural areas to enable such a shift.

The Lake Kinneret watershed is a rural region, and as part of the aforementioned solution in the future it is plausible to assume that parts of the pastures, croplands, and animal farming and grazing area, which are currently the major land-uses in the watershed, will be converted to high-density development urban areas. As these farming practices can have significant impacts on the water quality leaving the watershed (Berman 1998; Wang 2001), it is important to understand the likely impact of the anticipated changes in land-use. These changes are likely to affect the quality and quantity of the water flowing from the watershed into Lake Kinneret.

Lake Kinneret is the only large natural freshwater lake in Israel. Being such, it has a unique ecological value; it is an important focal point for water related tourism and a significant source of potable water. Thus, preserving the lake's ecology is crucial. To achieve this, all activities in the watershed, existing and possible future ones, must be seriously and carefully examined in relation to their potential effects on the lake. This work addresses this issue by assessing the possible effects of four future scenarios on the nutrients and sediment loads discharged from the watershed into the lake.

\subsection{Modeling Water Quality at the Watershed Scale}

Many distributed models have been used to simulate runoff generation and pollutant loads in Mediterranean watersheds, which is characterized, in general, by two distinct seasons: a dry, long, hot summer and a short rainy winter with a small number of flood events. Flood events are mainly associated with intensive, short-term rainfalls; high runoff rates occur very quickly and then just as quickly return to low base flow values (Bisantino et al. 2013). As typical for Mediterranean climate watersheds, the pollutant loads are predominantly contributed by a limited number of intense flood events, whereas the contribution of all of the other events is negligible. While somewhat limited, a number of studies have applied catchment level models to Mediterranean watersheds 


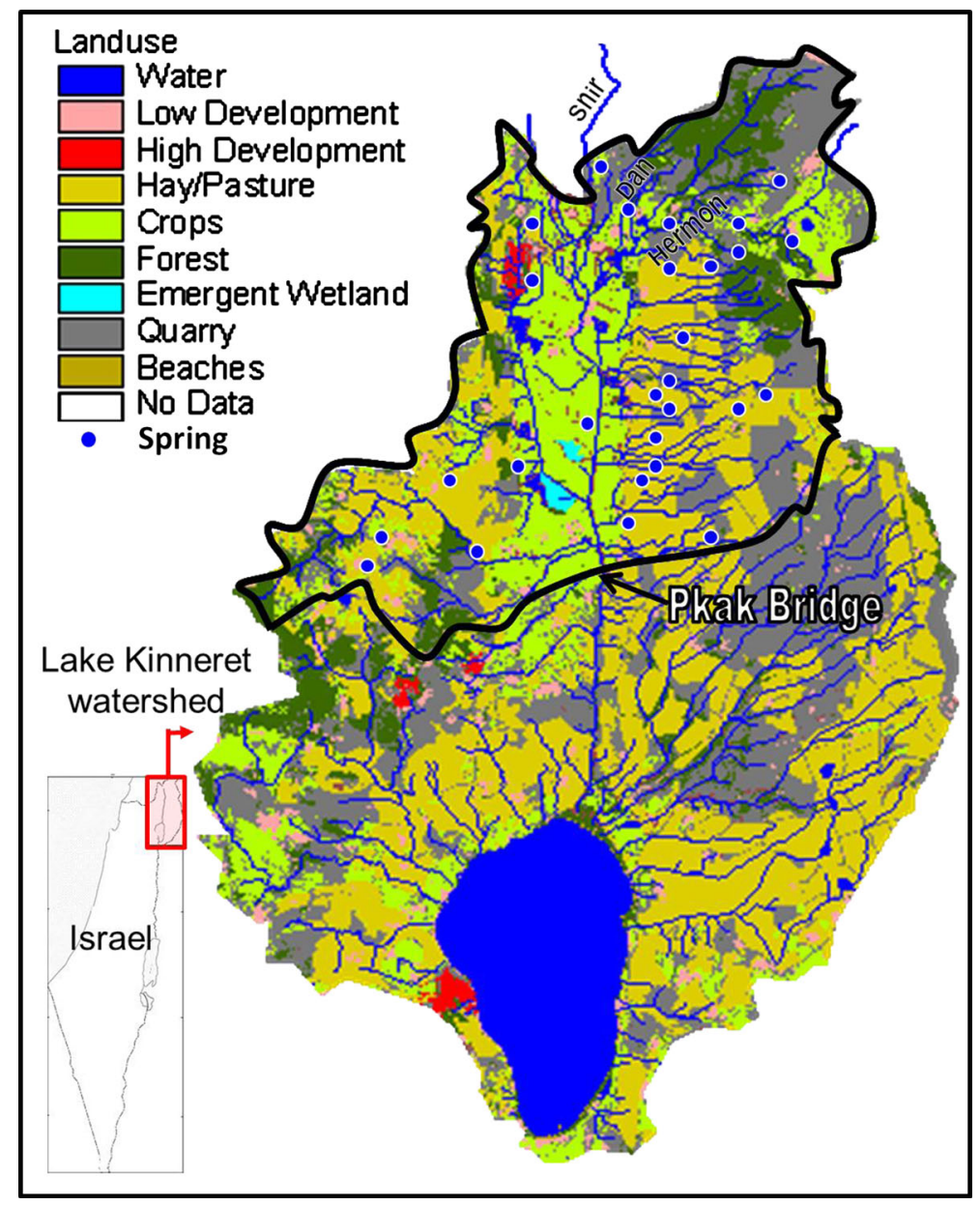

Fig. 1 The location of Lake Kinneret watershed in Israel and the land-use map of the study area: Lake Kinneret watershed. The sub-basins draining to the Pkak Bridge are marked with dark-black line. It also shows the main streams (Hermon, Dan and Snir)

(Gikas et al. 2006; Pisinaras et al. 2010; Licciardello et al. 2007; Bisantino et al. 2013; Chamoglou et al. 2014; Oroud 2015). These studies indicated that the model predictions were suitable for runoff and satisfactory for the sediment and nutrient loads.

Hydrological modeling of rainfall - stream flow relations in the Lake Kinneret watershed have also been examined in several studies (see review in Rimmer and Givati 2013). The most recent and updated model (Rimmer and Salingar 2006) simulated daily flows, originating from the karst region of the Hermon Mountain (north of Lake Kinneret watershed) as a function of daily precipitation and potential evaporation. However, only a limited number of models have been used to simulate pollutant loads in parts of Lake Kinneret watershed. In the most recent, Preis and Ostfeld (2008) presented a data driven modeling approach for flow and selected pollutant load predictions in a small sub-catchment within the Lake Kinneret watershed (Meshushim). The methodology comprised a coupled model-tree - genetic algorithm scheme. 
It produced a good fit in most cases, but had limited success in estimating peak flows and water quality loads.

These examples emphasize the need for a watershed model to efficiently predict both water quantity and essential water quality parameters such as sediments and nutrient loads for the Kinneret watershed, as part of an effort to assess the effects of possible future scenarios on water quality flowing downstream from the watershed to the lake. The watershed model we used for this study was the "ArcView Generalized Watershed Loading Function" (AVGWLF) model (Evans et al. 2002). The model provides an interface between ArcView geographic information system (GIS) software and the Generalized Watershed Loading Function (GWLF) model (Haith and Shoemaker 1987). GIS technology provides the means for compiling, organizing, manipulating, analyzing, and presenting spatially-referenced model input and output data. The model provides the ability to simulate runoff, sediment and nutrient $(\mathrm{N}$ and P) loadings from a watershed given variable-size source areas and land-uses (e.g., agricultural, forested, and developed; Evans et al. 2008). It is a continuous simulation model which uses daily time steps for meteorological input and water balance calculations. Sediment transport is calculated on a daily basis, while monthly stream bank erosion and nutrient loads are calculated based on daily water balances accumulated to monthly values. The AVGWLF model includes special algorithms for calculating the contribution of contaminating point sources: septic systems; nutrient loads associated with farm animals (Evans et al. 2008). The model has been tested extensively and successfully in the U.S. (Evans et al. 2008; Tu 2009; Georgas et al. 2009), Mexico (Carro et al. 2008), and Canada (Georgas et al. 2009).

In this study, we calibrated and verified AVGWLF to the Lake Kinneret watershed. We integrated AVGWLF model with two tools (HYMKE and MMF) to better represent unique hydrological characteristics of the specific region. The first tool was the HYdrological Model for Karst Environments (HYMKE; Rimmer and Salingar 2006), which was used for simulating daily spring flow in the Kinneret watershed as function of daily precipitation. The second tool is a Mediterranean multiplication factor (MMF) which was used to improve the prediction of sediment and nutrient load transport. The justification for using HYMKE and MMF is described below. Finally, we used the calibrated and verified combined AVGWLF-HYMKEMMF tool to analyze the effects of four possible extreme watershed management scenarios on the quantity and quality of water leaving the watershed and entering Lake Kinneret.

\section{Materials and Methods}

\subsection{Lake Kinneret Watershed and the Selected sub-Basin}

Lake Kinneret is the only large natural freshwater lake in Israel, with a surface area of approximately $165 \mathrm{~km}^{2}$, providing about $30 \%$ of the country's freshwater consumption. It lies at approximately $210 \mathrm{~m}$ below sea level in the northern part of the Great Afro-Syrian rift valley (Serruya 1978). The lake water is mainly used for providing potable water as well as for agricultural irrigation. The lake sustains sport and commercial fisheries, with an average annual yield of approximately 1,000 tons. In addition, it is a prime tourist attraction, as well as a world renowned religious site.

The Jordan River, the dominant contribution from the watershed to the lake, provides, on average, $70 \%$ of the inflowing water (Gal et al. 2003). The area of the Lake Kinneret watershed is about $2,730 \mathrm{~km}^{2}$ (of which $\sim 780 \mathrm{~km}^{2}$ are in Syria and Lebanon). In this study, 
we applied AVGWLF to a sub-basin of the Jordan River draining to the Pkak Bridge covering a total of $\sim 920 \mathrm{~km}^{2}$ (Fig. 1). The application to this sub-basin was performed because it constitutes the largest potential source of pollutant loading to the lake, and because stream flow and water quality are intensively measured at the Pkak Bridge station. More details regarding the Kinneret watershed hydrology can be found in: Berman (1998); Inbar and Bruins (2004); Rimmer and Salingar (2006); Rimmer and Givati (2013).

\subsection{Models Description}

\subsubsection{AVGWLF General Description}

The AVGWLF model requires various input files. These include specific parameters for each source-area considered (e.g., area size, curve number, etc.), global parameters that apply to all source areas such as initial storage and sediment delivery ratio, and various loading parameters for the different source areas. In addition, meteorological input is required and includes average daily temperature and daily precipitation $(\mathrm{mm})$ for the entire simulation period (Evans et al. 2008).

AVGWLF simulates surface runoff using the curve number $(\mathrm{CN})$ approach with daily temperature and precipitation inputs. Erosion and sediment yield are estimated using monthly erosion calculations based on the Universal Soil Loss Equation (USLE) algorithm. The integrated GIS part of AVGWLF requires various layers which describe the specific condition of the watershed, such as topography, distribution of soil types, land-use map (agriculture and urban uses including all combinations of surface cover and management), animal density, and meteorological records measured at distributed weather stations. Due to the fact that monitoring has been carried out in the watershed over several decades, the accuracy of the GIS layers data is considered to be high (for more details regarding the monitoring program please see Sukenik et al. 2014).

\subsubsection{Applying AVGWLF to Lake Kinneret Watershed}

Markel et al. (2006) previously applied AVGWLF (version 5.0) to the Lake Kinneret watershed, where the monthly sediment and nutrient calibration loads yielded reasonable agreement between simulated and measured values. Since springs play a significant role in the watershed of Lake Kinneret, but are not explicitly considered in the AVGWLF model, Markel et al. (2006) introduced them into the model as point sources. However, in the model, the calculations concerning point sources are carried out on a monthly time step. Therefore, spring flow and pollutants (N, P and sediments) loads data were introduced as monthly mean values. This structure of model input may be sufficient for reasonable verification, but it does not allow for prediction of water flow and pollutants transport in, and from the watershed, especially for time varying environmental conditions. In addition, the contribution of the Snir Basin, the largest topographic sub-basin that feeds the Jordan River, with nearly half of its water originating from large springs, was not simulated in that study, since most of its surface area is located in Lebanon, for which no hydrological data were available. It must be mentioned that both flows (springs and the Snir stream) comprise about $70 \%$ of the total flow in the Jordan River (Gal et al. 2003). Thus, there is a need to better simulate these flows and their associated loads. As this cannot be achieved solely by AVGWLF, we combined it with an additional external model, HYdrological Model for Karst Environment, HYMKE (Fig. 2). 
Fig. 2 Schematic diagram of integrating AVGWLF with HYMKE for calculating water flow at the Pkak Bridge

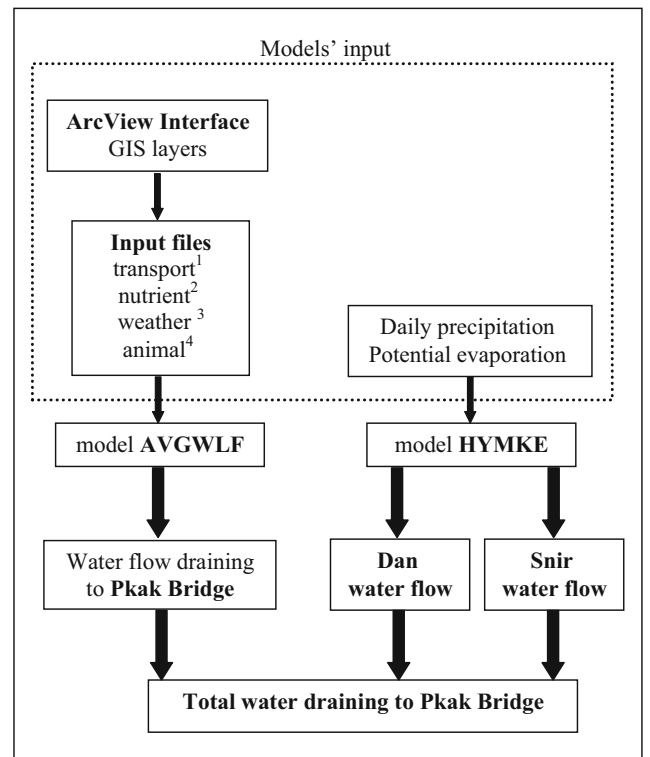

1. Transport file includes specific parameters for each source-area considered and global parameters that apply to all source.

2. Nutrient file includes nutrient loading for the different source areas.

3. Weather file includes meteorological input; average daily temperature and daily precipitation $(\mathrm{mm})$

4. Animal file includes basic animal information (e.g., types, populations, nutrient production rates), data on non-grazing animals and information pertaining to grazing animals.

HYMKE distinguishes between base- and surface- flow components of large-scale karst basins, and therefore, is especially suitable to model the contribution of large karstic springs (Rimmer and Salingar 2006). The model consists of four modules which address the surface layer, unsaturated zone, groundwater and surface flow. In HYMKE, the land surface of the entire geographical basin is recharged by precipitation and percolation to deeper layers, with surface runoff and appropriate volume reductions made as a result of evapotranspiration. For this study, the model was applied simultaneously to the three main tributaries of the Jordan River: Dan, Snir and Hermon streams. We used HYMKE to predict the flows of the Snir stream and Dan spring, and multiplied the Dan spring flow by a factor of 1.43 to represent the total flow of springs in the basin (the Dan Spring constitutes about $70 \%$ of the region's springs flow, according to the Israel Water Authority). Sediments and nutrients are not modeled in HYMKE; therefore, the loads of these pollutants in Snir stream (N, P and sediment loads) were derived by performing statistical analysis (linear regression) between their measured values in Snir stream and values detected at Pkak Bridge. The pollutant loads for the Dan stream were calculated using the point source module of AVGWLF.

It should be noted that springs are the major source of water in the Lake Kinneret watershed, while most of the pollution (sediment and nutrient loads) originates from surface runoffs. Thus, as AVGWLF cannot explicitly consider springs but it does simulate runoff pollution, and HYMKE does not simulate pollution but simulates springs, the integration of both models provides a useful tool.

Calibration and validation of the suite of tool was based on the cross-validation method, in which the data are split into two groups, one for calibration and the other for validation 
(Klemes 1986; Bennett et al. 2013). Calibration was conducted based on data from Jan 1990 through Dec 1999, while validation was performed based on the period from Jan 2000 through Dec 2004.

A fine-tuning method of key parameters (Evans et al. 2002; Markel et al. 2006) was used for calibrating the AVGWLF model to the selected sub-basin. According to this method, values for key parameters were adjusted within reasonable ranges to achieve an overall "best fit" between simulated and observed data. Table 1 contains all the key parameters, their initial and adjusted values. Since HYMKE was developed, calibrated and applied previously to the Snir and Dan Spring flows (Rimmer and Salingar 2006), it did not require further calibration. Both the coefficient of determination $\left(\mathrm{R}^{2}\right)$ and the Nash-Sutcliffe efficiency $(\mathrm{N}-\mathrm{S})$ were used to evaluate the goodness of fit between model predicted values and observed data (Zema et al. 2012, 2015).

\subsection{Precipitation Equation for Calculating Nutrient and Sediment Loads}

AVGWLF was originally developed for the North-East region of the USA where dry periods between consecutive rain events are relatively short. The Mediterranean climate of northern Israel constitutes two distinct seasons: a rainy winter from November to March and a long dry

Table 1 Initial and adjusted values of key parameters that were calibrated to the Lake Kinneret watershed

\begin{tabular}{|c|c|c|c|c|}
\hline Parameter & & $\begin{array}{l}\text { Initial } \\
\text { value }\end{array}$ & $\begin{array}{l}\text { Adjusted } \\
\text { value }\end{array}$ & Comments \\
\hline \multirow[t]{5}{*}{$\mathrm{CN}-\mathrm{Curve}$ numbers by source area } & Hay/Past & 43 & 40 & \multirow{5}{*}{$\begin{array}{l}\text { Initial value derived from GIS/ land cover } \\
\text { and soil maps }\end{array}$} \\
\hline & Cropland & 64 & 61 & \\
\hline & Forest & 37 & 34 & \\
\hline & Wetland & 69 & 65 & \\
\hline & Quarry $^{*}$ & 76 & 45 & \\
\hline \multirow[t]{2}{*}{ C-USLE factor by source area } & Cropland & 0.42 & 0.2 & \multirow{2}{*}{$\begin{array}{l}\text { Initial value derived from GIS/ soil and } \\
\text { land cover }\end{array}$} \\
\hline & Quarry $^{*}$ & 0.8 & 0.1 & \\
\hline \multirow{12}{*}{$\begin{array}{l}\text { Ket- monthly evapotranspiration } \\
\text { coefficients }\end{array}$} & Jan & 0.51 & 2.04 & \multirow[t]{12}{*}{ Initial values are default values } \\
\hline & Feb & 0.55 & 2.2 & \\
\hline & Mar & 0.58 & 2.32 & \\
\hline & Apr & 0.7 & 2.8 & \\
\hline & May & 0.78 & 3.12 & \\
\hline & Jun & 0.82 & 3.28 & \\
\hline & Jul & 0.84 & 3.36 & \\
\hline & Aug & 0.86 & 3.44 & \\
\hline & Sep & 0.86 & 3.3 & \\
\hline & Oct & 0.87 & 3.12 & \\
\hline & Nov & 0.87 & 2.7 & \\
\hline & Dec & 0.76 & 2.4 & \\
\hline \multicolumn{2}{|l|}{ Seepage coefficient } & 0 & 0.26 & Initial value is default value \\
\hline \multirow{2}{*}{$\begin{array}{l}\text { Background N/P concentrations in } \\
\text { GW }(\mathrm{mg} / \mathrm{L})\end{array}$} & $\mathrm{N}$ & 2.483 & 9 & \multirow{2}{*}{$\begin{array}{l}\text { Initial value derived from GIS/ back- } \\
\text { ground } \mathrm{N} \text { map }\end{array}$} \\
\hline & $\mathrm{P}$ & 0.028 & 0.15 & \\
\hline
\end{tabular}

* Quarry - In the case of Lake Kinneret "Quarry” in AVGWLF represents “open space” 
and hot summer extending through the remaining months. During summer, the soil becomes dry, and thus, as the rainy season begins, several rain events are often required in order to "restart" transport process of sediments and geochemical substances. Furthermore, even during winter, rain events are not evenly distributed and dry periods between consecutive events can be quite long. The average dry period between consecutive rain events (during winter) in the last 20 years in the basin was 6.5 days $( \pm 1.5 \mathrm{~d})$ and in most years at least one dry period of 30 days between consecutive events or more occurs (Rom et al. 2012). During these long dry periods the soil may become completely dry.

In AVGWLF, the USLE equation refers only to the current month precipitation and does not take into account the "history" of the hydrological system. However, we assume that in Mediterranean climates the previous month's precipitation may have a significant influence on the current monthly erosion transport (as shortly explained above). Therefore, in order to correct for this major difference between assumption at the base of the model originally constructed for a temperate climate region and actual conditions in the study area, we formulated a "Mediterranean multiplication factor" (MMF) by which we multiplied the output loads. The MMF is a power function (Eq. 1) based on precipitation during the current calendar month, precipitation during the previous month and the monthly average precipitation over a long period (15 years):

$$
\text { Load }=M M F \cdot \operatorname{Load}_{A V G W L F}
$$

$$
\begin{array}{ll}
\text { Apr } \leq \text { month } \leq \text { Oct } & M M F=1 \\
\text { Nov } \leq \text { month } \leq \text { Mar } & M M F=\left(\frac{\operatorname{simPrecip}(i)}{\operatorname{avePrecip}(i)}\right)^{y 1} \cdot\left(\frac{\operatorname{simPrecip}(i-1)}{\operatorname{avePrecip}(i-1)}\right)^{y 2}
\end{array}
$$

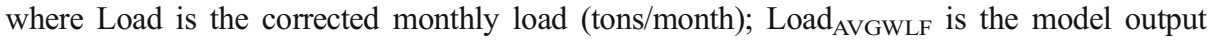
monthly load (tons/month); simPrecip(i) is the precipitation during month $\mathrm{i}(\mathrm{mm} / \mathrm{month})$; avePrecip(i) is the average precipitation during month $\mathrm{i}(\mathrm{mm} / \mathrm{month})$, calculated over 15 years; y 1 and $y 2$ are constants determined by a calibration process. The ratio between simPrecip and avePrecip and the values of y1 y2 (integer or fraction) determine the tendency of the MMF (i.e., increasing or decreasing $\operatorname{Load}_{\mathrm{AVGWLF}}$ ).

The implemented MMF correction is not a process-based addition to the model but rather a pragmatic solution to the impact of the long dry periods during the winter unaccounted for in the original model. As described below, it was implemented differently to TSS, TP and TN. Furthermore, this type of model correction is often reported in the literature. Tolson and Shoemaker (2007) used a similar approach with the SWAT2000 to simulate the transport of flow, sediments and phosphorus to the Cannonsville Reservoir in upstate New York. In their case, they performed the modifications regarding excess soil water movement in frozen soils and soil erosion predictions under snow cover.

\subsection{Description of the Studied Scenarios}

The calibrated, verified and integrated tool (AVGWLF, HYMKE and MMF) was used for studying the effects of four watershed management scenarios on the quantity and quality of water leaving the watershed. The scenarios examined the effects of various changes to the agricultural activities in the watershed and the effects of increasing the residential area in the watershed. The effects of land-use changes, due to increased urbanization was conducted first by converting pasture areas to urban areas (high-density development, scenario 1) or by 
converting $90 \%$ of the crop land to urban areas (scenario 2) without modifying other parameters (Table 2). The effects of farm animals were studied by either increasing the number of animals by an order of magnitude (scenario 3) or by transferring all farm animals, including livestock and dairy farms, from the watershed area (scenario 4; Table 2). The rationale for studying scenario 3 was the option to strengthen the commercial competitiveness of the agricultural activities in the watershed by increasing the intensity of animal farming and the number of grazing animals in the watershed. These scenarios were created by modifying the number of farm animals (without modifying other parameters) in the farm animals input file.

Each scenario was run for the period Jan 2000 through Dec 2004. The results of the scenarios were compared to the reference run that describes the actual situation in the watershed during those years. It should be noted that the scenarios purposely comprise of extremes conditions (sometime beyond plausible future development), in order to magnify the possible effects on the quantity and quality of the watershed water. Therefore, we consider the relative changes and possible effects on the aquatic environment as the key issues and the changes to the absolute values of loads and flows of minor importance.

\section{Results and Discussion}

\subsection{Water Flow Calibration}

The daily flow calibration results for the period 1990-1999 demonstrated good correlation between predicted and observed daily water volumes with $\mathrm{R}^{2}=0.81$ and $\mathrm{N}-\mathrm{S}=0.79$ (Fig. 3). The daily flow verification (period 2000-2004) also yielded a good match between predicted

Table 2 Four watershed management scenarios examined using the AVGWLF - HYMKE - MMF approach for Jan 2000 - Dec 2004

\begin{tabular}{|c|c|c|c|c|c|c|}
\hline \multirow[t]{2}{*}{ Parameter } & \multirow{2}{*}{$\begin{array}{l}\text { Reference } \\
\text { value }\end{array}$} & \multirow[t]{2}{*}{ Units } & \multicolumn{4}{|l|}{ Scenario } \\
\hline & & & $\begin{array}{l}\text { 1: } \\
\text { No grazing; high } \\
\text { urban develop }\end{array}$ & $\begin{array}{l}\text { 2: } \\
\text { Reduced crop, high } \\
\text { develop }\end{array}$ & $\begin{array}{l}\text { 3: } \\
\text { Increased animal } \\
\text { farming }\end{array}$ & $\begin{array}{l}\text { 4: } \\
\text { No farm } \\
\text { animals }\end{array}$ \\
\hline Dairy cows & 3,180 & $\begin{array}{r}\text { Head } \\
\text { no. }\end{array}$ & 0 & 3,180 & 31,800 & 0 \\
\hline Beef cows & 12,000 & $\begin{array}{r}\text { Head } \\
\text { no. }\end{array}$ & 0 & 12,000 & 120,000 & 0 \\
\hline Sheep & 5,743 & $\begin{array}{r}\text { Head } \\
\text { no. }\end{array}$ & 0 & 5,743 & 57,430 & 0 \\
\hline Hay/Past & 19,184 & Ha & 0 & 19,184 & 19,184 & 19,184 \\
\hline Cropland & 16,237 & $\mathrm{Ha}$ & 16,237 & 1,623 & 16,237 & 16,237 \\
\hline Forest & 9,827 & $\mathrm{Ha}$ & 9,827 & 9,827 & 9,827 & 9,827 \\
\hline Wetland & 390 & На & 390 & 390 & 390 & 390 \\
\hline Quarry & 18,700 & На & 18,700 & 18,700 & 18,700 & 18,700 \\
\hline Transition & 1,239 & $\mathrm{Ha}$ & 1,239 & 1,239 & 1,239 & 1,239 \\
\hline Lo_Int_Dev & 1,896 & $\mathrm{Ha}$ & 1,896 & 1,896 & 1,896 & 1,896 \\
\hline Hi_Int_Dev & 327 & $\mathrm{Ha}$ & 19,511 & 14,941 & 327 & 327 \\
\hline
\end{tabular}

Lo_Int_Dev and Hi_Int_Dev described urban area low and high-density development 

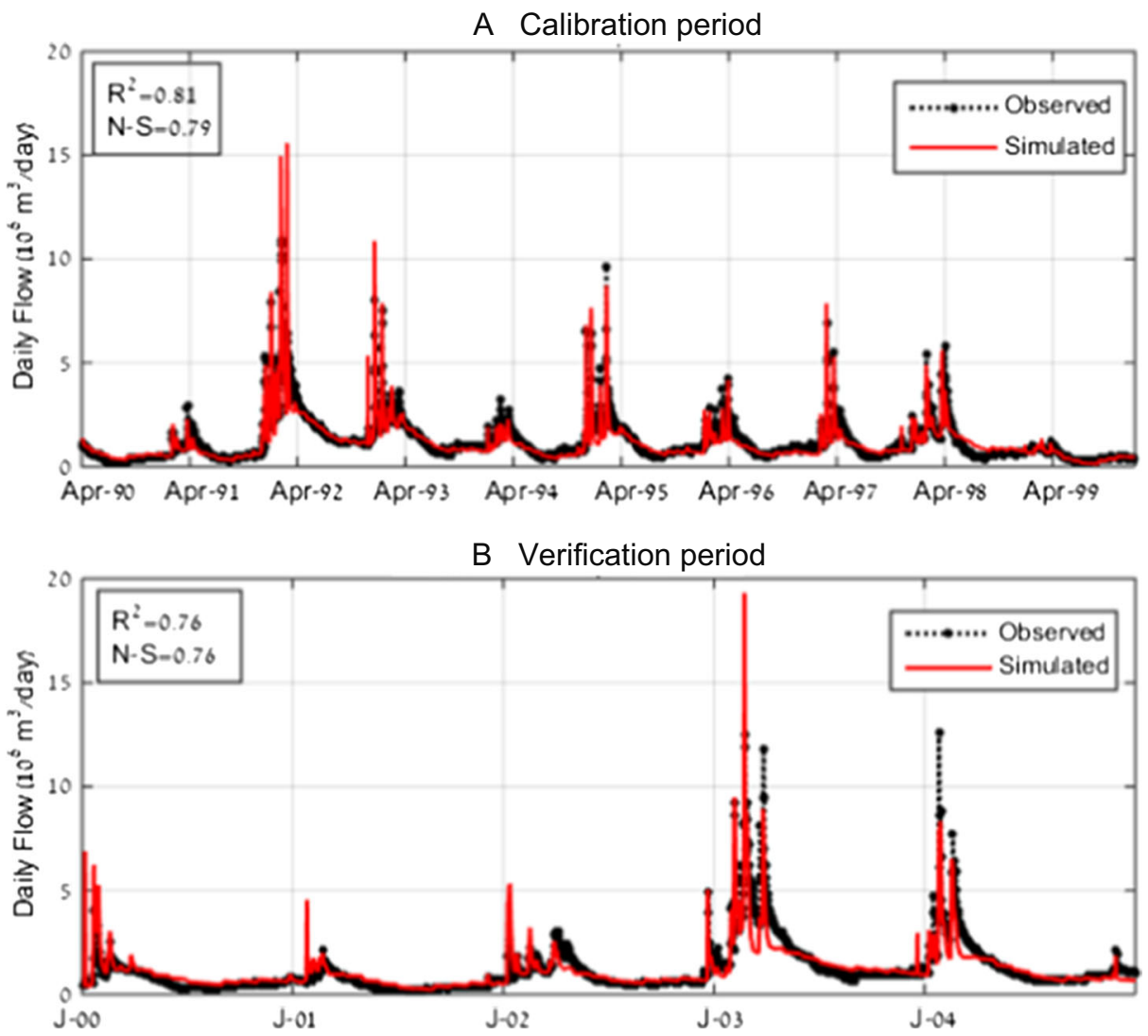

Fig. 3 Simulated and measured daily flows at the Pkak Bridge during the calibration period (1990-1999) and the verification period (2000-2004). The simulated curve represents the sum of the water flow from both the AVGWLF and HYMKE models

and observed daily water volumes $\left(\mathrm{R}^{2}=0.76, \mathrm{~N}-\mathrm{S}=0.76\right.$; Fig. 4). Both high values indicate that the model not only succeeded in predicting the flow pattern but also in predicting the extreme values even though relatively high variability in the daily flow volumes was obvious during the simulated period. It should be emphasized that the seasonal variability of the Mediterranean climate is expressed in large differences between the extreme and the average daily flows. Within the Kinneret watershed, a difference of one order of magnitude was found between the extreme daily flowrate and the average flow, and two orders of magnitude between the highest and lowest daily flow, based on 15 years of data (1990-2004). Large variations in daily flows were found even on an annual scale when only a few months separate the highest and the lowest daily flows. Large variability in seasonal flowrates and between years represents a challenge to correctly simulate the observed patterns. Even so, using the integrated models (AVGWLF- HYMKE), the prediction of the daily flow of all major Jordan River sources resulted in high $\mathrm{R}^{2}$ and N-S values. The ability of the model to simulate highly variable conditions, such as the case here with the daily flowrates, provides increased confidence in model output (Bennett et al. 2013).

The match between the measured flowrate and the simulated values is in good agreement with the quality of model calibration of the Jordan River flow performed by Rimmer and 
Salingar (2006) with $\mathrm{R}^{2} \cong 0.8$. Mediterranean studies (see section 1.2) also indicated similar agreement, with $\mathrm{R}^{2}$ ranging between 0.71 and 0.89 (Gikas et al. 2006; Licciardello et al. 2007; Bisantino et al. 2013; Zema et al. 2015).

\subsection{Sediment and Nutrient Calibration}

The base calibration of the sediment and nutrient loads yielded satisfactory results (Table 3). It appears that the model predicted fairly well the trends in the loads, but was less successful in predicting the high peak values (Fig. 4). The same tendency was observed for the verification period (Table 3 and Fig. 4). In this case, the $\mathrm{R}^{2}$ and N-S values were higher for the verification period since it was a shorter period that included less extreme transport load events than the calibration period.

To improve model simulation accuracy, we used the MMF (Eq. 1) with which we multiplied the base calibration output loads. Since most of the phosphorus in the water is associated with suspended solids, it acts like TSS; and their power constants (y1 and y2) should be similar. Calibration yielded $\mathrm{y} 1=0.25$ and $\mathrm{y} 2=0.5$ for TSS and TP. The MMF was used for the TN load with different power parameters. It is most likely that this difference originates from the fact that the nitrogen is dissolved (unlike phosphorus and TSS which are particulate). The best parameters for the $\mathrm{TN}$ were $\mathrm{y} 1=0.7$ and $\mathrm{y} 2=0.5$.

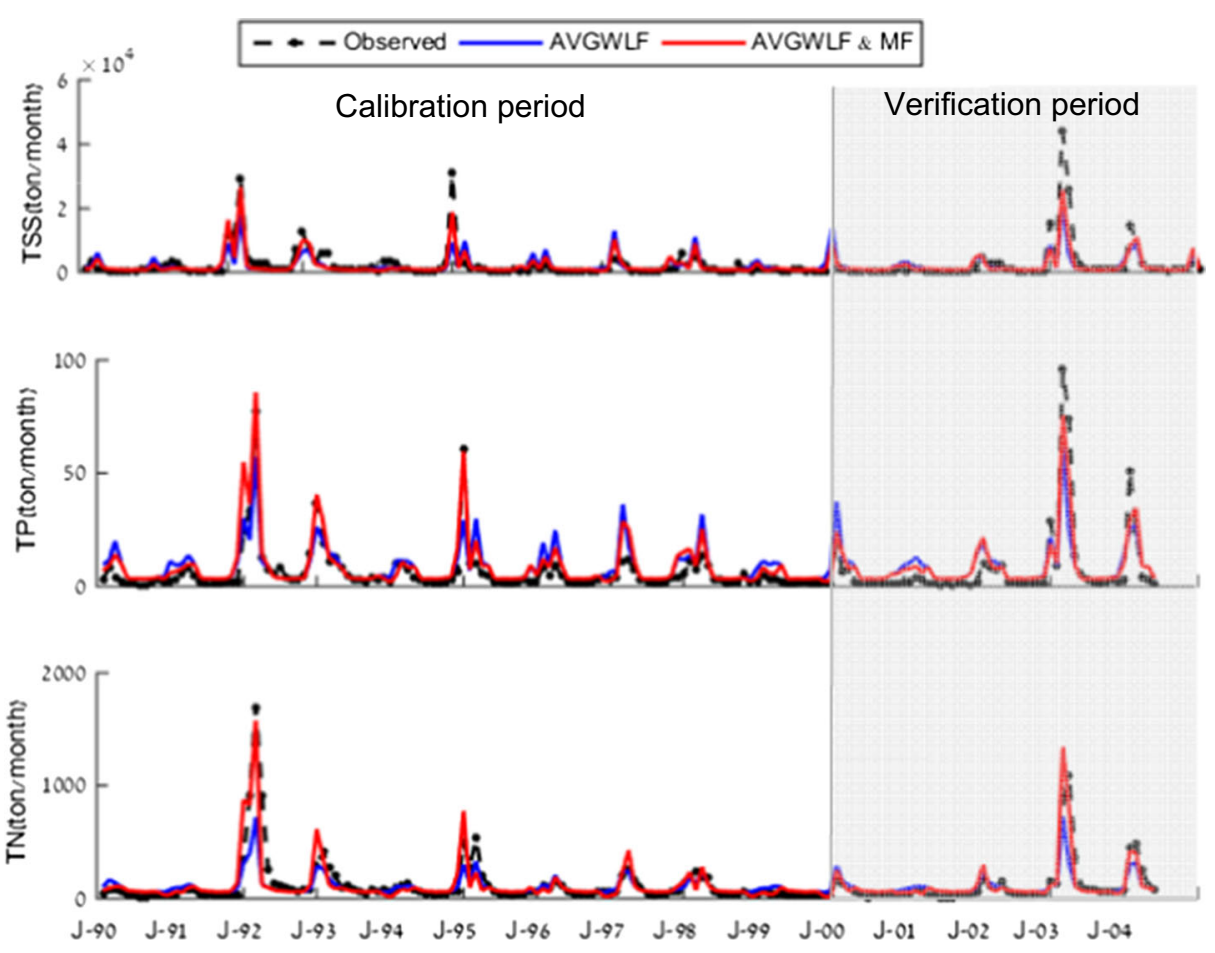

Fig. 4 Comparison between simulated and observed monthly loads (top - sediments; centre - TP; bottom - TN) at the Pkak Bridge during the calibration period (1990-1999) and the verification period (2000-2004) without (blue line) and with (red line) the MMF 
Table 3 Performance of TSS, TN and TP load simulations with and without the Mediterranean multiplication factor (MMF)

\begin{tabular}{|c|c|c|c|c|c|c|c|}
\hline & & \multicolumn{3}{|c|}{ AVGWLF } & \multicolumn{3}{|c|}{ AVGWLF \& MMF } \\
\hline & & TSS & $\mathrm{TP}$ & $\mathrm{TN}$ & TSS & $\mathrm{TP}$ & $\mathrm{TN}$ \\
\hline \multirow[t]{2}{*}{ Calibration period } & $\mathrm{R}^{2}$ & 0.49 & 0.64 & 0.77 & 0.78 & 0.87 & 0.70 \\
\hline & $\mathrm{N}-\mathrm{S}$ & 0.56 & 0.58 & 0.56 & 0.69 & 0.73 & 0.69 \\
\hline \multirow[t]{2}{*}{ Verification period } & $\mathrm{R}^{2}$ & 0.69 & 0.72 & 0.67 & 0.84 & 0.88 & 0.79 \\
\hline & $\mathrm{N}-\mathrm{S}$ & 0.58 & 0.67 & 0.59 & 0.72 & 0.67 & 0.76 \\
\hline
\end{tabular}

The tendency of the MMF (i.e., increasing or decreasing $\operatorname{Load}_{\mathrm{AVGWLF}}$ ) is affected by the ratio between the monthly precipitation (simPrecip) and the monthly average precipitation (avePrecip).

Once the MMF was used, correlations between predicted and observed TSS, TP and TN loads were greatly improved (Table 3, Fig. 4) for both the calibration and verification periods. Variation in values was large and ranged between one order of magnitude between the extreme and average loads and over two orders of magnitude between the highest and the lowest loads. Similar to the daily flowrate, large variations in loads were also found on an annual scale and although the seasonal cycle was maintained between years, there were large differences between the peak values during the period examined. For example, the TP load increased by a factor of 6.7 in 1 year (from Feb. 2001 to Feb. 2002) and by a factor of 22 in 2 years (from Feb. 2001 to Feb. 2003). Despite these large variations in seasonal loads and the difference between years, the suite of models successfully reproduced the observed patterns of high variability. This is of key importance as the majority of the annual sediment transport rate is concentrated in a relatively small number of high-magnitude flow events, and therefore, it is difficult in prediction (Bisantino et al. 2013).

These nutrient and sediment load calibration and verification results are in line with other calibration processes of GWLF. Chang et al. (2001) found $R^{2}>0.8$ in most cases of six watersheds in Pennsylvania. Gikas et al. (2006), using SWAT2000, achieved $R^{2}$ values between 0.40 and 0.98 for sediments, $0.51-0.87$ for nitrates, and $0.50-0.82$ for phosphorus for a watershed in Northern Greece.

\subsection{Scenario Analysis}

The calibrated integrated model was used for studying the effects of four extreme scenarios as described above. As aforementioned, in order to enhance the effects, we purposely applied extreme conditions, thus, in the context of the scenario analyses, we consider the relative changes and possible effects on the aquatic environment as the key issues and the changes to the absolute values of loads and flows of minor importance.

\subsubsection{Water Flow}

Daily water flow at the Pkak Bridge was affected, as expected, only by those scenarios that altered water usage or flow in the catchment. So, while changing the number of farm animals (scenarios 3 and 4) did not influence the daily flowrate, changing land-use did have an impact. Changing land-use from pasture (scenario 1) or agriculture (scenario 2) to urban area increased 
the water flow during rain events. In scenario 1 , the daily flow during rain events increased by up to $40 \%$ than the reference run and in scenario 2 increased by up to $20 \%$. Urbanization increases surface flow, by creating more impervious surfaces such as pavement and buildings that do not allow percolation of the water through the soil. Changing land-uses increased water flow only during high rain events (about 50 cases in each scenario) while during most of the days the flowrates were approximately the same for the reference run and the two scenarios. The total water flowrate changed only by $2.9 \%$ and $1.5 \%$ in scenarios 1 and 2 , respectively, indicating a negligible increase in water flow over the 5-year period. Hence, scenarios 1 and 2 did not change the overall flowrate, but did lead to increased extreme flowrates (during significant rain events). This new condition may require changes in water flow management in the future.

\subsubsection{Sediments Loads}

All four scenarios affected the estimated sediment loads leaving the watershed (Table 4). Scenario 2, in which $90 \%$ of the agriculture lands were converted to urban areas, produced the most significant changes where the load increased by up to a factor of 4 . This increase is the result of major damage and total removal of streamside vegetation to the point where it no longer provides bank stability, and cause a dramatic increase in bank erosion. When such large scale land clearing for agriculture takes place runoff increases, and the stream channel will adjust to accommodate additional flow by increasing stream bank erosion. The stream bank erosion is well simulated by the AVGWLF model, more information on the specific details of the model approach is provided in Evans et al. (2002). An increase in the number of farm animals (scenario 3) generated the second most notable change with an increase in sediment load by up to $90 \%$ as compared to the reference run. This was due to the fact that increasing the number of farm animals increased grazing, which in turn enhanced the stream bank erosion. Although scenarios 1 and 4 included a decrease in farm animals, the simulations yielded increased sediment monthly loads of up to $20 \%$ and $30 \%$, respectively (Table 4). However, the difference between the total sediment loads over 5 years in these two latter scenarios and the reference run was less that $8 \%$, which indicates a negligible increase in sediment load.

\subsubsection{Nutrient Loads}

Farm animals are a major source of nutrients, thus changing their numbers in the watershed is expected to affect nutrient loads. An increase in the number of farm animals by a factor of 10

Table 4 The ratio between the four scenarios and the reference run for TSS, TN and TP

\begin{tabular}{llllll}
\hline & & $\begin{array}{l}\text { Scenario 1/ } \\
\text { Reference }\end{array}$ & $\begin{array}{l}\text { Scenario 2/ } \\
\text { Reference }\end{array}$ & $\begin{array}{l}\text { Scenario 3/ } \\
\text { Reference }\end{array}$ & $\begin{array}{l}\text { Scenario 4/ } \\
\text { Reference }\end{array}$ \\
\hline TSS & Average (SD) & $1.1(0.1)$ & $3.5(1.0)$ & $1.8(0.3)$ & $1.2(0.1)$ \\
& Range & $0.8-1.3$ & $1.1-4.0$ & $1.1-1.9$ & $1.0-1.2$ \\
TN & Average (SD) & $0.9(0.1)$ & $1.0(0.03)$ & $1.9(0.9)$ & $0.9(0.1)$ \\
& Range & $0.7-1.0$ & $0.9-1.1$ & $1.1-4.3$ & $0.6-1.0$ \\
TP & Average (SD) & $0.8(0.1)$ & $1.0(0.04)$ & $3.1(1.0)$ & $0.8(0.1)$ \\
& Range & $0.5-0.9$ & $0.8-1.1$ & $1.3-6.2$ & $0.4-1.0$ \\
\hline
\end{tabular}

$S D$ Standard deviation. Monthly data for 4 years 
(scenario 3), increased (as expected) the nutrient loads from this particular source 10 fold and increased the total loads by average values of $3.1( \pm 1.1)$ and $1.9( \pm 0.9)$ for TP and TN, respectively (Table 4). The loads especially increased during the rainy season (winter) by up to 6.2 and 4.3 fold for TP and TN, respectively. Reducing the number of farm animals in scenarios 1 and 4, decreased the TP and TN loads by a factor of up to $0.4-0.5$ and $0.6-0.7$, respectively. Scenario 2 had a negligible influence on nutrient loads. In this scenario, cropland areas were reduced; therefore, nutrient loads produced from this source decreased. However, the scenario included an increase in urban area leading to enhanced runoff from this source and more intensive stream bank erosion. As a result, the loads were comparable to the loads in the reference run.

Changes in nutrient loads can have a large impact on the downstream lake ecosystem by changing the ratio between $\mathrm{TN}$ to $\mathrm{TP}$, which will determine the plankton dominance and create favorable conditions for undesirable plankton bloom. These changes can be critical given the importance of the lake as a drinking water resource and as a site for recreation.

\section{Conclusions}

Simulations based on AVGWLF integrated with the HYMKE model can be used for determining the extent and magnitude of water flow and non-point source pollution in the Mediterranean climate watershed of Lake Kinneret. Integrating the MMF significantly improved the calibration and verification of sediment and nutrient loads, and therefore, is believed to be essential in characterizing these processes in a Mediterranean climate.

The integrated tool (AVGWLF-HYMKE-MMF) was used to examine four extreme management scenarios in the watershed. Though there was no significant change in the total volume of water leaving the watershed in scenarios 1 and 2 (converting agricultural land to high-density development urban areas), scenario 2 produced increased flows during high rain events, which would have detrimental impacts on human activities.

The successful combination of the models provides watershed and lake managers the ability to examine the potential land-use changes and their impact on the watershed and the lake downstream.

\section{References}

Bennett ND, Croke BFW, Guariso G, Guillaume JHA, Hamilton SH, Jakeman AJ, Marsili-Libelli S, Newham LTH, Norton JP, Perrin C, Pierce SA, Robson B, Seppelt R, Voinov AA, Fath BD, Andreassian V (2013) Characterising performance of environmental models. Environ Model Softw 40:1-20

Berman T (1998) Lake kinneret and its watershed: international pressures and environmental impacts. Water Policy 1:193-207

Bisantino T, Bingner R, Chouaib W, Gentile F, Trisorio Liuzzi G (2013) Estimation of runoff, peak discharge and sediment load at the event scale in a medium-size Mediterranean watershed using the AnnAGNPS model. Land Degrad Dev. doi:10.1002/ldr.2213

Carro MM, Davila JI, Balandra AG, Lopez RH, Delgadillo RH, Chavez JS, Inclan LB (2008) Importance of diffuse pollution control in the patzcuaro lake basin in Mexico. Water Sci Technol 58:2179-2186

Chamoglou M, Papadimitriou T, Kagalou I (2014) Key-descriptors for the functioning of a Mediterranean reservoir: the case of the New lake Karla-Greece. Environ Proc 1:127-135

Chang H, Evans BM, Easterling DR (2001) The effects of climate change on stream flow and nutrient loading. J Am Water Resour Assoc 37(4):973-985 
Evans BM, Lehning DW, Corradini KJ, Petersen GW, Nizeyimana E, Hamlett JM, Robillard PD and Day RL (2002) A comprehensive GIS-based modelling approach for predicting nutrient loads in watersheds. Journal of Spatial Hydrology, 2(2)

Evans BM, Lehning DW and Corradini KJ (2008) AVGWLF manual. Version 7.1. Penn State Institutes of Energy and the Environment. The Pennsylvania State University. University Park, PA 16802

Gal G, Imberger J, Zohary T, Antenucci JP, Anis A, Rosenberg T (2003) Simulating the thermal dynamics of lake kinneret. Ecol Model 162:69-86

Georgas N, Rangarajan S, Farley KJ, Jagupilla SCK (2009) AVGWLF-based estimation of nonpoint source nitrogen loads generated within long island sound sub-watersheds. J Am Water Resour Assoc 45(3):715733

Gikas GD, Yiannakopoulou T, Tsihrintzis VA (2006) Modeling of non-point source pollution in a Mediterranean drainage basin. Environ Model Assess 11:219-233

Haith DA, Shoemaker LL (1987) Generalized watershed loading functions for stream flow nutrients. Water Resour Bull 23(3):471-478

Inbar M, Bruins HJ (2004) Environmental impact of multi-annual drought in the Jordan kinneret watershed, Israel. Land Degrad Dev 15(13):243-256

Klemes V (1986) Operational testing of hydrological simulation models. Hydrol Sci J 31(1):13-24

Licciardello F, Zema DA, Zimbone SM, Bingner RL (2007) Runoff and soil erosion evaluation by the AnnAGNPS model in a small Mediterranean watershed. Trans ASABE 50(5):1585-1593

Markel D, Somma F, Evans BM (2006) Using a GIS transfer model to evaluate pollutant loads in the lake kinneret watershed, Israel. Water Sci Technol 53(10):75-82

Oroud IM (2015) Water budget assessment within a typical semiarid watershed in the eastern Mediterranean. Environ Proc 2:395-409

Pisinaras V, Petalas C, Gikas GD, Gemitzi A, Tsihrintzis VA (2010) Hydrological and water quality modeling in a medium-sized basin using the soil and water assessment tool (SWAT). Desalination 250(1):274-286

Preis A, Ostfeld A (2008) A coupled model tree-genetic algorithm scheme for flow and water quality predictions in watersheds. J Hydrol 349(3-4):364-375

Rimmer A and Givati A (2013) The hydrology of Lake Kinneret. In "Lake Kinneret - Ecology and Management”. Zohary T., Sukenik A., Berman T. and, Nishri A. [eds]. Springer (in preparation)

Rimmer A, Salingar Y (2006) Modelling precipitation-streamflow processes in karst basin: the case of the Jordan river sources, Israel. J Hydrol 331:524-542

Rom M, Berger D, Sarusi F and Teltsch B (2012) Report on Lake Kinneret Watershed: Winter 2011/12. Mekorot - Israel National Water Company. 68 p. (in Hebrew)

Serruya C (1978) Lake Kinneret. Dr. W. Junk, The Hague, 501 p

Sukenik A, Zohary T, Markel D (2014) The monitoring program in lake kinneret. Springer, Netherlands, pp 561575

Tolson BA, Shoemaker CA (2007) Cannonsville reservoir watershed SWAT2000 model development, calibration and validation. J Hydrol 337:68-86

Tu J (2009) Combined impact of climate and land use changes on streamflow and water quality in eastern Massachusetts, USA. J Hydrol 379:268-283

Wang X (2001) Integrating water-quality management and land-use planning in a watershed context. J Environ Manag 61:25-36

Zema DA, Bingner RL, Denisi P, Govers G, Licciardello F, Zimbone SM (2012) Evaluation of runoff, peak flow and sediment yield for events simulated by the AnnAGNPS model in a Belgian agricultural watershed. Land Degrad Dev 23(3):205-215

Zema DA, Denisi P, Taguas Ruiz EV, Gomez JA, Bombino G, Fortugno D (2015) Evaluation of surface runoff prediction by AnnAGNPS model in a large Mediterranean watershed covered by olive groves. Land Degrad Dev. doi:10.1002/ldr.2390 